\title{
Patent Ductus Arteriosus, Indomethacin, and Intestinal Distension: Effects on Intestinal Blood Flow and Oxygen Consumption
}

\author{
REBECKA L. MEYERS, GAD ALPAN. EMIL LIN, AND RONALD I. CLYMAN \\ Cardiovascular Research Institute and the Departments of Pediatrics, Surgery, and Pharmacy, University of \\ California at San Francisco, San Francisco, California 94143
}

\begin{abstract}
To determine the relative importance of patent ductus arteriosus, indomethacin, and intestinal distension as factors that promote terminal ileum ischemia, eight near-term fetal lambs were surgically prepared by in situ cannulation of the proximal and distal ends of a loop of terminal ileum, formalin infiltration of the ductus arteriosus, and placement of a snare around the ductus arteriosus to control its patency. The incisions were closed; the lambs were delivered and mechanically ventilated. Terminal ileum blood flow and oxygen consumption were measured after the loop of ileum had been distended with $0.9 \% \mathrm{NaCl}$ to luminal pressures of 1-2, 7, and $18 \mathrm{~mm} \mathrm{Hg}(0.13-0.26$, 0.93 , and $2.38 \mathrm{kPa}$ ) (pressures observed in the intestinal lumen after feeding and during pathologic conditions). The effect of these pressures on terminal ileum blood flow and oxygen consumption was examined: $l$ ) with ductus closed, 2) with ductus open, and 3) $1 \mathrm{~h}$ after administration of indomethacin $(0.3 \mathrm{mg} / \mathrm{kg} ; 0.8 \mu \mathrm{mol} / \mathrm{kg})$ with ductus closed. Both open ductus and indomethacin produced a significant decrease in intestinal blood flow. This occurred over the entire range of luminal pressures examined. In all three study conditions, terminal ileum blood flow fell commensurate with a fall in perfusion pressure. Despite this absence of pressure-flow autoregulation, oxygen consumption was maintained when the ductus was closed or open. In contrast, indomethacin inhibited the ability of the terminal ileum to autoregulate its oxygen consumption. These findings suggest that both open ductus and indomethacin present an increased risk of intestinal ischemia. We hypothesize that indomethacin's beneficial effect on ductus closure may be counterbalanced by its negative effect on intestinal perfusion and metabolism. (Pediatr Res 29: 569-574, 1991)
\end{abstract}

Abbreviations

NEC, necrotizing enterocolitis

PDA, patent ductus arteriosus

$\dot{\mathrm{V}}_{2}$, oxygen consumption

Numerous risk factors have been associated with intestinal ischemia: among these are PDA and, more recently, the treat-

Received August 21, 1990; accepted January 31, 1991.

Correspondence and reprint requests: Ronald I. Clyman, M.D., Box 0544, HSE 1403, University of California at San Francisco, San Francisco, CA 94143.

Supported by Pulmonary Special Center of Research Grant HL 27356 from the United States Public Health Service, a National Research Service Award, Training Grant HL 07192-12 (R.L.M.), and an American Heart Association, California Affiliate Fellowship (with funds contributed by the San Mateo County chapter) (G.A.). ment of a PDA with indomethacin (1-6). In sick, preterm infants, where intestinal oxygen demands are high (7) and motility is frequently compromised, enteral feedings can lead to increased oxygen demand (8), intestinal distension, venous congestion, and decreased perfusion (9).

The following study was designed to examine the independent and combined effects of a PDA, indomethacin, and intestinal distension on the terminal ileum's ability to regulate its blood flow and oxygen metabolism in the newborn lamb. We hypothesized that if there was a preexisting decrease in terminal ileum perfusion caused by a PDA or indomethacin, superimposed intestinal distension might decrease perfusion further, leading to terminal ileum blood flows below the level capable of supporting oxidative metabolism. The terminal ileum was chosen as the site of study for two reasons. First, in the newborn, the terminal ileum is particularly susceptible to ischemia because collateral blood flow is not yet fully developed (10). Second, the terminal ileum is the portion of the bowel most frequently afflicted with NEC (11).

\section{MATERIALS AND METHODS}

Surgical preparation. Surgery was performed in utero in eight pregnant mixed-breed Western ewes with time-dated gestation of 139-142 d (term $147 \mathrm{~d}$ ). The ewes were fasted $24 \mathrm{~h}$, given spinal anesthesia with $4 \mathrm{~mL} 1 \%$ tetracaine, and sedated as needed with i.v. ketamine (50-100 mg every 15-20 min). Local anesthesia with $0.5 \%$ lidocaine was used for all maternal and fetal incisions. In addition, the fetal lambs received supplemental anesthesia with i.v. pentobarbital sodium (5-10 mg in intermittent doses). The uterus was exposed through a midline abdominal incision and, using surgical techniques previously described in detail (12), catheters were placed into the fetal lamb's descending aorta, brachiocephalic artery, superior and inferior vena cava, and carotid artery. Also as described previously (12), through a small left anterior thoracotomy, the wall of the ductus arteriosus was infiltrated with a $10 \%$ formalin solution to destroy its muscular layer and prevent postnatal closure. A mechanical snare was then placed around the ductus arteriosus to control its patency experimentally. A catheter was placed in the main pulmonary artery and the thoracotomy incision closed. Next, as shown in Figure 1, we prepared an in situ, isolated loop of terminal ileum about $40 \mathrm{~cm}$ long. Silastic cannulas were placed in the proximal and distal ends of the study loop of terminal ileum and into the proximal intestine. Through the ligated colonic venous tributary, a catheter was placed into the mesenteric vein draining the study loop of terminal ileum. The abdominal incision was closed. Finally, a $4.0 \mathrm{~F}$, cuffed endotracheal tube was placed by tracheotomy. The lambs were delivered by cesarean section.

Experimental protocol. The experiment began at the time of delivery. First, the lambs were stabilized on mechanical ventila- 
tion for 2.5 h. Initial mechanical ventilator settings (fractional inspired oxygen $=1.0$, positive inspiratory pressure $=25 \mathrm{~cm}$ $\mathrm{H}_{2} \mathrm{O}$, positive end expiratory pressure $=3 \mathrm{~cm} \mathrm{H}_{2} \mathrm{O}$, rate $=40$ / $\mathrm{min})$ were decreased to mean settings of fractional inspired oxygen $=0.3 \pm 0.1$, positive inspiratory pressure $=21 \pm 3 \mathrm{~cm}$ $\mathrm{H}_{2} \mathrm{O}$, positive end expiratory pressure $=3 \pm 0.2 \mathrm{~cm} \mathrm{H}_{2} \mathrm{O}$, rate $=$ $19 \pm 4 / \mathrm{min}$; subsequently, settings were adjusted as necessary to maintain arterial $\mathrm{PCO}_{2}$ at $30-35 \mathrm{~mm} \mathrm{Hg}(3.97-4.64 \mathrm{kPa})$ and $\mathrm{PO}_{2}$ at $90-115 \mathrm{~mm} \mathrm{Hg}(11.92-15.33 \mathrm{kPa})$. The lambs were dried with a towel and covered with a plastic sheet to reduce evaporative heat loss. Rectal temperature was maintained at $38-39^{\circ} \mathrm{C}$ with an Aquamatic K-pad (American Hospital Supply, McGaw Park, IL) and with radiant heat lamps. Throughout the experiment, the lambs were sedated with intermittent i.v. pentobarbital (5 mg as necessary to suppress the corneal reflex). A continuous infusion of $5 \%$ dextrose in $0.25 \% \mathrm{NaCl}(10 \mathrm{~mL} / \mathrm{kg} / \mathrm{h})$ was started. Fresh whole fetal or maternal blood, collected from the placenta and ewe at the time of delivery, was transfused to replace all blood loss from experimental sampling. The study loop of terminal ileum and the proximal bowel were kept decompressed by placing the intestinal cannulas to gravity drainage. The tip of the carotid arterial catheter was directed retrograde, under pulsewave guidance, into the left ventricle.

After $2.5 \mathrm{~h}$ stabilization on mechanical ventilation, each lamb ( $n=8$, mean weight $3.47 \pm 0.67 \mathrm{~kg}$, mean gestational age 141 $\pm 1 \mathrm{~d})$ was studied under three different experimental conditions: open ductus, closed ductus, and indomethacin + closed ductus. The lambs were studied first with the ductus arteriosus open at three different terminal ileum luminal pressures, $1-2,7$, and 18 $\mathrm{mm} \mathrm{Hg}\left(2-3,10\right.$, and $25 \mathrm{~cm} \mathrm{H}_{2} \mathrm{O} ; 0.13-0.26,0.93$, and 2.38 $\mathrm{kPa})$. The luminal pressure was $1-2 \mathrm{~mm} \mathrm{Hg}(0.13-0.26 \mathrm{kPa})$ with the intestinal cannulas open to gravity drainage; it was increased to $7 \mathrm{~mm} \mathrm{Hg}(0.93 \mathrm{kPa})$, then $18 \mathrm{~mm} \mathrm{Hg}(2.38 \mathrm{kPa})$, by passive gravity distension with a solution of warm $0.9 \% \mathrm{NaCl}$ and drained enteric secretions. After $5 \mathrm{~min}$ of equilibration at each luminal pressure, we withdrew arterial and mesenteric venous blood samples and measured vascular pressures and blood flows. Arterial and mesenteric venous blood samples were analyzed for $\mathrm{pH}, \mathrm{PCO}_{2}, \mathrm{PO}_{2}, \% \mathrm{O}_{2}$ saturation, and $\mathrm{Hb}$ concentration. Vascular pressures were measured in the descending aorta, terminal ileum mesenteric vein, pulmonary artery, and left ven- tricle. Blood flows, including terminal ileum blood flow, cardiac output, and ductus arteriosus left to right shunt, were measured by injection of microspheres $(15 \mu \mathrm{m})$ labeled with one of nine different isotopes into the left ventricle as reference blood samples were withdrawn simultaneously from the descending aorta and brachiocephalic artery (12). After measurements at each luminal pressure were completed, the intestinal cannulas were replaced to gravity drainage for a recovery period of $20 \mathrm{~min}$ before proceeding to measurements at the next luminal pressure.

After open-ductus measurements were complete, the ductus was closed by tightening the snare placed around it. Thirty min later, the same measurements were made at each of the three luminal pressures. We then gave the lamb a $0.3-\mathrm{mg} / \mathrm{kg}(0.8$ $\mu \mathrm{mol} / \mathrm{kg}$ ) dose of indomethacin and, $1 \mathrm{~h}$ later with the ductus closed, the same measurements were repeated at the three luminal pressures. In addition, I-mL blood samples were obtained 1 and $2 \mathrm{~h}$ after the dose of indomethacin to determine its plasma concentration. At the end of the experiment, the animals were given an overdose of Euthanasia solution (Anthony Products, Arcadia, CA). As tissues were prepared for microsphere analysis, the positions of all catheters and the ductus arteriosus snare were confirmed.

Measurements and calculations. Arterial and venous $\mathrm{pH}, \mathrm{PCO}_{2}$, and $\mathrm{PO}_{2}$ were measured on a Corning Blood Gas Analyzer (Corning Medical, Medfield, MA); oxygen saturation and $\mathrm{Hb}$ concentration were measured on an OSM 2 Hemoximeter (Radiometer, Copenhagen, Denmark). Vascular catheters were connected to Statham $\mathrm{P} 23 \mathrm{~dB}$ pressure transducers and vascular pressures continuously recorded on a Beckman R612 direct writing recorder. For microsphere determination of blood flows, the organs and tissues were weighed, placed in formalin, incinerated at $325^{\circ} \mathrm{C}$ for $72 \mathrm{~h}$, pulverized, and placed in counting vials. The radionuclide activity of each isotope in each organ and reference blood sample was measured as radioactive counts in a well-type gamma scintillation counter and multichannel pulseheight analyzer. Terminal ileum blood flow was then calculated from the counts recovered in the terminal ileum, divided by the counts in the reference arterial blood sample, multiplied by the reference blood flow. Blood withdrawn from the mesenteric vein during the microsphere injection had no radioactivity, indicating that there was no terminal ileum arterial-venous shunting or

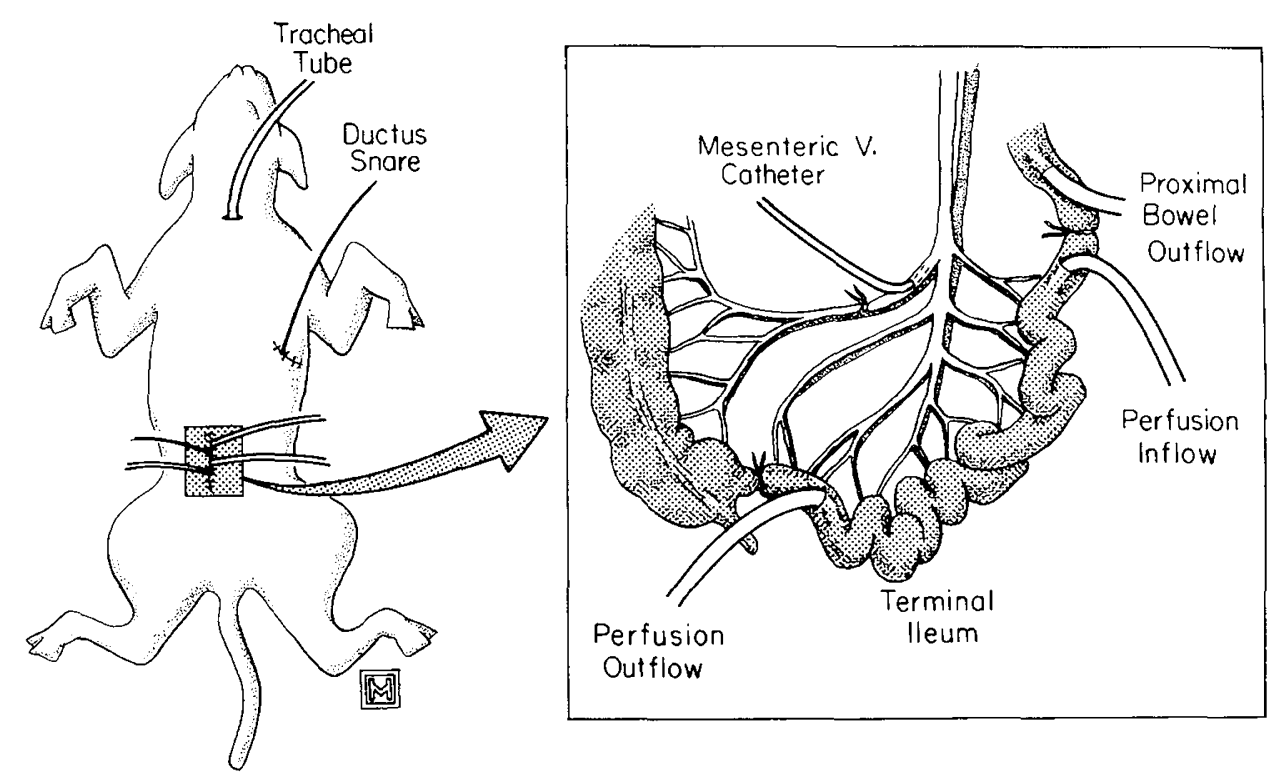

Fig. 1. Surgical preparation of the in situ, isolated loop of terminal ileum in eight newborn lambs. After proximal and distal ligation of the terminal ileum (about $40 \mathrm{~cm}$ long), 8 F Silastic cannulas were placed for proximal perfusion inflow, distal perfusion outflow, and proximal bowel outflow. All cannulas were put to gravity drainage except during experimental measurements. A catheter was placed into the mesenteric vein draining the study loop of terminal ileum through the ligated colonic venous tributary. The intestine was replaced in the abdomen; the abdominal incision was closed. 
leaching of microspheres from the terminal ileum capillary bed. Cardiac output and ductus arteriosus shunt flow were calculated from the counts recovered in the entire animal, the counts recovered in the lungs, the counts in the reference samples, reference blood flow, and an assumed bronchial arterial blood flow of $8 \%$ of cardiac output (12).

Terminal ileum perfusion pressure was determined as the difference between aortic driving pressure and effective "venous" outflow pressure. Because increases in luminal pressure are transmitted almost completely to the venous compartment, when luminal pressure is increased effective "venous" outflow equals luminal pressure. Oxygen consumption was determined as the product of the arterial-to-venous oxygen content difference and terminal ileum blood flow. Arterial and venous oxygen content were determined as the product of $\mathrm{Hb}$ concentration, oxygen saturation, and an oxygen binding capacity of $1.35 \mathrm{~mL} / \mathrm{g} \mathrm{Hb}$.

Indomethacin concentrations were determined by combining $0.1 \mathrm{~mL}$ plasma with $0.5 \mathrm{~mL}$ internal standard solution (Carprofen $0.1 \mu \mathrm{g} / \mathrm{mL}$ in $\mathrm{CH}_{3} \mathrm{CN}$ ). After centrifugation, an aliquot of the upper layer was injected for HPLC analysis into an Altex Ultrasphere Octyl $5-\mu \mathrm{m}(5 \mathrm{~cm} \times 4.6 \mathrm{~mm})$ column using a $40 \%$ $\mathrm{CH}_{3} \mathrm{CN}+0.2 \% \mathrm{H}_{3} \mathrm{PO}_{4}$, pH 4, mobile phase, and detected at 260 $\mathrm{nm}$ wavelength with a UV detector.

Statistical analysis. The comparisons to be made were determined before we began this study. The effects of ductal patency and indomethacin at each luminal pressure, and the effects of luminal pressure within each study condition, were tested by analysis of variance for repeated measures. When ANOVA revealed significant differences, we used Scheffé's multiple comparison $F$ for a posteriori comparisons. ANOVA for terminal ileum vascular resistance was performed after the values were logarithmically transformed to normalize their distribution. Within each study condition, the relationship between changes in oxygen consumption and changes in intestinal perfusion pressure was determined by simple linear regression, as performed by a computerized statistical package, Super ANOVA, based on the principle of least squares; a normal distribution of the residuals in each regression was confirmed by box-plot analysis. All values are presented as mean $\pm \mathrm{SD}$. Values of $p<0.05$ are considered statistically significant.

\section{RESULTS}

Arterial $\mathrm{pH}, \mathrm{PCO}_{2}$, and $\mathrm{PO}_{2}$ did not change throughout the course of the study (Table 1). When the ductus arteriosus was closed, cardiac output and vascular pressures were within the normal range for mechanically ventilated newborn lambs (12, 13). When the ductus arteriosus was open, there was a left to right shunt through the ductus arteriosus that was $60 \%$ of left ventricular output. This was accompanied by a compensatory increase in cardiac output, an increase in pulmonary arterial and left ventricular end-diastolic pressures, and a decrease in descending aortic arterial pressure. When the ductus was open, there was a significant drop in terminal ileum blood flow. This was due both to a drop in aortic driving pressure and to an increase in terminal ileum vascular resistance.

When the lambs were treated with indomethacin $(0.3 \mathrm{mg} / \mathrm{kg}$; $0.8 \mu \mathrm{mol} / \mathrm{kg}$ ), there was a transient increase in aortic blood pressure (data not shown); however, $1 \mathrm{~h}$ later there were no significant differences in cardiac output or blood pressures when compared to pretreatment values (Table 1). Plasma indomethacin concentrations at 1 and $2 \mathrm{~h}$ after the dose were $0.637 \pm 0.199$ $\mu \mathrm{g} / \mathrm{mL}\left(1.8 \pm 10^{-6} \mathrm{M}\right)$ and $0.485 \pm 0.098 \mu \mathrm{g} / \mathrm{mL}\left(1.4 \times 10^{-6}\right.$ $\mathrm{M})$, respectively. These values are comparable to those obtained in human clinical trials where indomethacin has been used to constrict the ductus arteriosus (for review, see reference 14). Indomethacin significantly decreased terminal ileum blood flow. This was due solely to an increase in intestinal vascular resistance.

Elevated luminal pressure increases intestinal wall tension, which causes the effective intestinal venous outflow pressure to increase. Therefore, we hypothesized that terminal ileum perfusion pressure (the difference between aortic driving pressure and effective intestinal venous outflow pressure) would drop as terminal ileum luminal pressure was increased. Surprisingly, however, when the luminal pressure was raised to $7 \mathrm{~mm} \mathrm{Hg}(0.93$ $\mathrm{kPa}$ ), the terminal ileum perfusion pressure fell only when the ductus was open (Table 1). In both the closed ductus, and indomethacin + closed ductus study conditions, net perfusion pressure was unchanged, despite the increase in luminal pressure, due to an unexpected compensatory increase in aortic driving pressure. However, when luminal pressure was increased further to $18 \mathrm{~mm} \mathrm{Hg}(2.38 \mathrm{kPa})$, perfusion pressure was significantly decreased in all three study conditions. As one might expect, because perfusion pressure was not affected by the increase in luminal pressure to $7 \mathrm{~mm} \mathrm{Hg}(0.93 \mathrm{kPa})$, terminal ileum blood flow was not altered. However, when the luminal pressure was increased to $18 \mathrm{~mm} \mathrm{Hg}(2.38 \mathrm{kPa})$, perfusion pressure dropped, causing terminal ileum blood flow to fall in all three study conditions.

Figure 2 shows the relationship between terminal ileum oxygen consumption and perfusion pressure. It appears, from the horizontal slope of the regression line, that oxygen consumption was relatively maintained, or autoregulated, when the ductus was closed or open (Fig. $2 a$ and $b$ ). However, this ability to autoregulate intestinal oxygen consumption was compromised after treatment with indomethacin (Fig. 2c).

\section{DISCUSSION}

Our purpose was to study the perinatal effects of a PDA, indomethacin, and superimposed intestinal distension on terminal ileum blood flow and oxygen consumption in newborn lambs. The lambs in this study were sedated with pentobarbital, which theoretically could affect the results. Pentobarbital has been reported to increase intestinal blood flow transiently; however, intestinal blood flow usually returns to baseline in about an hour despite continuing pentobarbital anesthesia (15). In this study, several hours had elapsed between the first dose of pentobarbital and our measurements of blood flow; therefore, it is unlikely that pentobarbital sedation affected our results. Our lamb model does not allow for speculation on the effects of prolonged ductus patency, or repeated administration of indomethacin. Nor do our findings reflect upon very immature bowel; the lambs in this study were only slightly premature. To answer these questions, a different experimental model would be required. Our aim was to create a model in which increases in terminal ileum luminal pressure could be reproducibly produced and then to determine whether ductus patency or indomethacin would significantly decrease terminal ileum blood flow or oxygen consumption.

The physiologic, and pathologic clinical, range of distal intestinal pressure in adult laboratory animals and humans is reported to be about $0-20 \mathrm{~mm} \mathrm{Hg}(0-2.65 \mathrm{kPa})(16)$. Normal sustained basal pressure generally lies somewhere between 2 and $4 \mathrm{~mm} \mathrm{Hg}$ $(0.26-0.52 \mathrm{kPa})(16)$. Maximum mean sustained pressure has been reported as high as $30 \mathrm{~mm} \mathrm{Hg}(3.97 \mathrm{kPa})$ in a model of adynamic ileus in the dog (17), although most authors agree that maximum sustained pressure in abnormally distended intestine lies somewhere between 13 and $18 \mathrm{~mm} \mathrm{Hg}(1.72-2.38 \mathrm{kPa})(16$, 18). Unfortunately, there have been no similar studies that examine distal intestinal pressures in newborns.

Artificial intestinal distension, with the associated increase in luminal pressure, has been shown to decrease terminal ileum blood flow in several studies in adult dogs and cats and in newborn piglets (19-23). The mechanism that causes blood flow to fall is reported to be mechanical compression of the venous blood vessels. Increases in luminal pressure are transmitted almost completely to the venous compartment; effective "venous" outflow pressure is increased, causing perfusion pressure and blood flow to fall (22). However, the clinical applicability of 
Table 1. Comparison of physiologic and hemodynamic variables, terminal ileum perfusion pressure, vascular resistance, and blood flow*

\begin{tabular}{|c|c|c|c|c|c|c|c|c|c|}
\hline & \multicolumn{9}{|c|}{ Terminal ileum luminal pressure $[\mathrm{mm} \mathrm{Hg}(\mathrm{kPa})]$} \\
\hline & \multicolumn{3}{|c|}{ Closed ductus } & \multicolumn{3}{|c|}{ Open ductus } & \multicolumn{3}{|c|}{ Indomethacin + closed ductus } \\
\hline & $1-2(0.1-0.3)$ & $7(0.9)$ & $18(2.4)$ & $1-2(0.1-0.3)$ & $7(0.9)$ & $18(2.4)$ & $1-2(0.1-0.3)$ & $7(0.9)$ & $18(2.4)$ \\
\hline \multicolumn{10}{|l|}{ Arterial blood gases } \\
\hline $\mathrm{pH}$ & $7.40 \pm 0.05$ & $7.40 \pm 0.05$ & $7.39 \pm 0.05$ & $7.41 \pm 0.04$ & $7.40 \pm 0.11$ & $7.45 \pm 0.07$ & $7.41 \pm 0.02$ & $7.39 \pm 0.07$ & $7.40 \pm 0.06$ \\
\hline \multicolumn{10}{|c|}{ 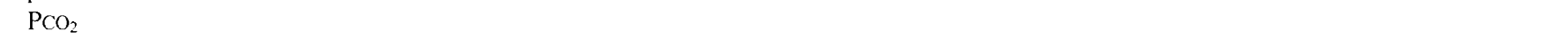 } \\
\hline$(\mathrm{mm} \mathrm{Hg})$ & $32 \pm 4$ & $34 \pm 5$ & $35 \pm 5$ & $35 \pm 4$ & $29 \pm 6$ & $31 \pm 3$ & $33 \pm 3$ & $31 \pm 3$ & $32 \pm 3$ \\
\hline$(\mathrm{kPa})$ & $4.2 \pm 0.5$ & $4.5 \pm 0.7$ & $4.6 \pm 0.7$ & $4.5 \pm 0.5$ & $3.8 \pm 0.8$ & $4.1 \pm 0.4$ & $4.4 \pm 0.4$ & $4.1 \pm 0.4$ & $4.2 \pm 0.4$ \\
\hline \multicolumn{10}{|l|}{$\mathrm{PO}_{2}$} \\
\hline (mm Hg) & $100 \pm 27$ & $95 \pm 41$ & $83 \pm 22$ & $101 \pm 18$ & $115 \pm 28$ & $105 \pm 22$ & $114 \pm 38$ & $97 \pm 28$ & $113 \pm 33$ \\
\hline$(\mathrm{kPa})$ & $13.2 \pm 3.6$ & $12.6 \pm 5.4$ & $11.0 \pm 2.9$ & $13.4 \pm 2.4$ & $15.2 \pm 3.7$ & $13.9 \pm 2.9$ & $15.1 \pm 5.0$ & $12.8 \pm 3.7$ & $15.0 \pm 4.4$ \\
\hline $\begin{array}{l}\text { Cardiac output } \\
(\mathrm{mL} / \mathrm{min} / \mathrm{kg})\end{array}$ & $180 \pm 36$ & $179 \pm 37$ & $179 \pm 37$ & $284 \pm 64 \dagger$ & $306 \pm 117+$ & $258 \pm 68 \S$ & $149 \pm 31$ & $139 \pm 35$ & $155 \pm 36$ \\
\hline Left to right shunt\| & $13 \pm 13$ & $12 \pm 14$ & $12 \pm 12$ & $60 \pm 8+$ & $61 \pm 9+$ & $62 \pm 7+$ & $12 \pm 11$ & $7 \pm 8$ & $12 \pm 10$ \\
\hline \multicolumn{10}{|l|}{ Vascular pressure } \\
\hline \multicolumn{10}{|l|}{$\mathrm{MAP}_{\mathrm{AO}}$} \\
\hline$(\mathrm{mm} \mathrm{Hg})$ & $63 \pm 11$ & $67 \pm 9 \pi$ & $68 \pm 10^{* *}$ & $55 \pm 12 \dagger$ & $56 \pm 12 \div$ & $55 \pm 11 \div$ & $58 \pm 11$ & $64 \pm 99$ & $65 \pm 11^{* *}$ \\
\hline$(\mathrm{kPa})$ & $8.3 \pm 1.5$ & $8.9 \pm 1.29$ & $9.0 \pm 1.3^{* *}$ & $7.3 \pm 1.6 \dagger$ & $7.4 \pm 1.6+$ & $7.3 \pm 1.5 \ddagger$ & $7.7 \pm 1.5$ & $8.5 \pm 1.2 \pi$ & $8.6 \pm 1.5^{* *}$ \\
\hline \multicolumn{10}{|c|}{ - } \\
\hline$(\mathrm{mm} \mathrm{Hg})$ & $28 \pm 6$ & $30 \pm 9$ & $29 \pm 6$ & $45 \pm 7 \ddagger$ & $48 \pm 9 \ddagger$ & $46 \pm 7 \ddagger$ & $25 \pm 4$ & $24 \pm 9$ & $26 \pm 4$ \\
\hline$(\mathrm{kPa})$ & $3.7 \pm 0.8$ & $4.0 \pm 1.2$ & $3.8 \pm 0.8$ & $6.0 \pm 0.9+$ & $6.4 \pm 1.2 \ddagger$ & $6.1 \pm 0.9 \pm$ & $3.3 \pm 0.5$ & $3.2 \pm 1.2$ & $3.4 \pm 0.5$ \\
\hline \multicolumn{10}{|l|}{ LVED } \\
\hline$(\mathrm{mm} \mathrm{Hg})$ & $2.8 \pm 3.1$ & $2.6 \pm 2.9$ & $1.9 \pm 2.1$ & $8.7 \pm 4.6 \dagger$ & $6.7 \pm 2.2 \S$ & $8.2 \pm 5.0 \dagger$ & $1.7 \pm 1.8$ & $1.8 \pm 1.9$ & $3.3 \pm 3.0$ \\
\hline$(\mathrm{kPa})$ & $0.4 \pm 0.4$ & $0.3 \pm 0.4$ & $0.3 \pm 0.3$ & $1.2 \pm 0.6 \dagger$ & $0.9 \pm 0.3 \S$ & $1.1 \pm 0.7 \dagger$ & $0.2 \pm 0.2$ & $0.2 \pm 0.3$ & $0.4 \pm 0.4$ \\
\hline \multicolumn{10}{|l|}{ Terminal ileum } \\
\hline \multicolumn{10}{|l|}{ Perfusion pressure } \\
\hline $\begin{array}{l}(\mathrm{mm} \mathrm{Hg}) \\
(\mathrm{kPa})\end{array}$ & $\begin{array}{l}61 \pm 11 \\
8.1 \pm 1.5\end{array}$ & $\begin{array}{c}59 \pm 9 \\
7.8 \pm 1.2\end{array}$ & $\begin{array}{l}49 \pm 10+\uparrow \\
6.5 \pm 1.3+\dagger\end{array}$ & $\begin{array}{c}54 \pm 12 \S \\
7.2 \pm 1.6 \S\end{array}$ & $\begin{array}{l}48 \pm 12 \uparrow, 9 \\
6.4 \pm 1.6 \dagger, \emptyset\end{array}$ & $\begin{array}{l}36 \pm 11 \uparrow, \uparrow \\
4.8 \pm 1.5 \dagger, \dagger \dagger\end{array}$ & $\begin{array}{c}59 \pm 11 \\
7.8 \pm 1.5\end{array}$ & $\begin{array}{l}57 \pm 9 \\
7.5 \pm 1.2\end{array}$ & $\begin{array}{l}46 \pm 11 \dagger \dagger \\
6.1 \pm 1.5+\dagger\end{array}$ \\
\hline $\begin{array}{l}\text { Vascular resistance } \\
\text { (mm } \mathrm{Hg} / \mathrm{mL} . \\
\left.\min ^{-1} \cdot 100 \mathrm{~g}^{-1}\right)\end{array}$ & $0.9 \pm 0.5$ & $0.9 \pm 0.4$ & $0.9 \pm 0.3$ & $1.5 \pm 0.7 \S$ & $1.6 \pm 0.8 \S$ & $1.6 \pm 0.8 \S$ & $1.7 \pm 0.8 \S$ & $1.8 \pm 0.7 \dagger$ & $1.9 \pm 0.9 \S$ \\
\hline $\begin{array}{l}\text { Blood flow } \\
(\mathrm{mL} / \mathrm{min} / 100 \mathrm{~g})\end{array}$ & $79 \pm 29$ & $76 \pm 35$ & $59 \pm 16$ & $41 \pm 16+$ & $38 \pm 17 \dagger$ & $27 \pm 13,+1$ & $56 \pm 29 \S$ & $49 \pm 25 \S$ & $33 \pm 19 \S$ \\
\hline
\end{tabular}

* Measurements were made at three different terminal ileum luminal pressures with the ductus arteriosus closed, open, and closed after treatment with indomethacin. Data are mean $\pm \mathrm{SD}$ in eight lambs. MAP $\mathrm{AO}_{\mathrm{O}}$, mean arterial pressure in descending aorta; $\mathrm{PA}$, mean pulmonary artery pressure; LVED, left ventricular end-diastolic pressure.

$\dagger p<0.01$ compared to closed ductus study condition.

$\ddagger p<0.001$ compared to closed ductus study condition.

$\S p<0.05$ compared to closed ductus study condition.

$\| \%$ of cardiac output shunted left to right across the ductus arteriosus.

I $p<0.05$ compared to terminal ileum luminal pressure of $1-2 \mathrm{~mm} \mathrm{Hg}$.

${ }^{* *} p<0.01$ compared to terminal ileum luminal pressure of $1-2 \mathrm{~mm} \mathrm{Hg}$.

$\dagger p<0.001$ compared to terminal ileum luminal pressure of $1-2 \mathrm{~mm} \mathrm{Hg}$.

these studies is somewhat unclear because, in most, the range of intestinal pressures analyzed greatly exceeded that seen under physiologic and pathologic clinical conditions (16). The few studies that have included an analysis of increases in luminal pressure below $20 \mathrm{~mm} \mathrm{Hg}(2.65 \mathrm{kPa})$ often failed to show a decrease in terminal ileum blood flow in this range. One study in newborn piglets, however, suggests that terminal ileum blood flow is compromised at a lower luminal pressure in the newborn (23). We hypothesized that increases in luminal pressure in the physiologic range might be less well tolerated in an intestine already compromised by a PDA or indomethacin.

Previous animal studies have shown that both a PDA (12) and indomethacin (24) decrease mesenteric blood flow. Doppler ultrasonographic evidence suggests that both a PDA (25) and indomethacin (26) also may decrease mesenteric blood flow in preterm infants. In the current study, we found that the presence of either a PDA or indomethacin decreased terminal ileum blood flow over the entire range of intestinal luminal pressures examined. The fall in terminal ileum blood flow with a PDA tended to be slightly greater than the fall in terminal ileum blood flow with indomethacin, but the magnitude of the decreases was not statistically different. Indomethacin, unlike other nonsteroidal antiinflammatory drugs, acts as a potent vasoconstrictor of regional vascular beds (e.g., the gastrointestinal and myocardial circulations) (27-29). In adult dogs and cats, indomethacin has been shown to decrease intestinal blood flow by a mechanism independent of decreases in perfusion pressure, $\alpha$-adrenoreceptors, or prostaglandin synthesis blockade $(30,31)$. We have previously shown that a PDA reduces mesenteric perfusion by causing both a decrease in arterial perfusion pressure and an increase in mesenteric vascular resistance (12).

As we increased terminal ileum luminal pressure to $7 \mathrm{~mm} \mathrm{Hg}$ $(0.93 \mathrm{kPa})$, we saw a surprising compensatory increase in descending aortic driving pressure, causing intestinal perfusion pressure to be maintained. We do not know what caused this compensatory increase. One possibility would be a neurogenic reflex in which intestinal distension stimulates vagal afferents, ultimately resulting in an increase in arterial pressure. Another possibility is that increased intestinal pressure, a known mediator of visceral pain in conditions such as colic or intestinal obstruction (32), may have resulted in increased catecholamine secretion, causing a secondary increase in arterial pressure. It is 

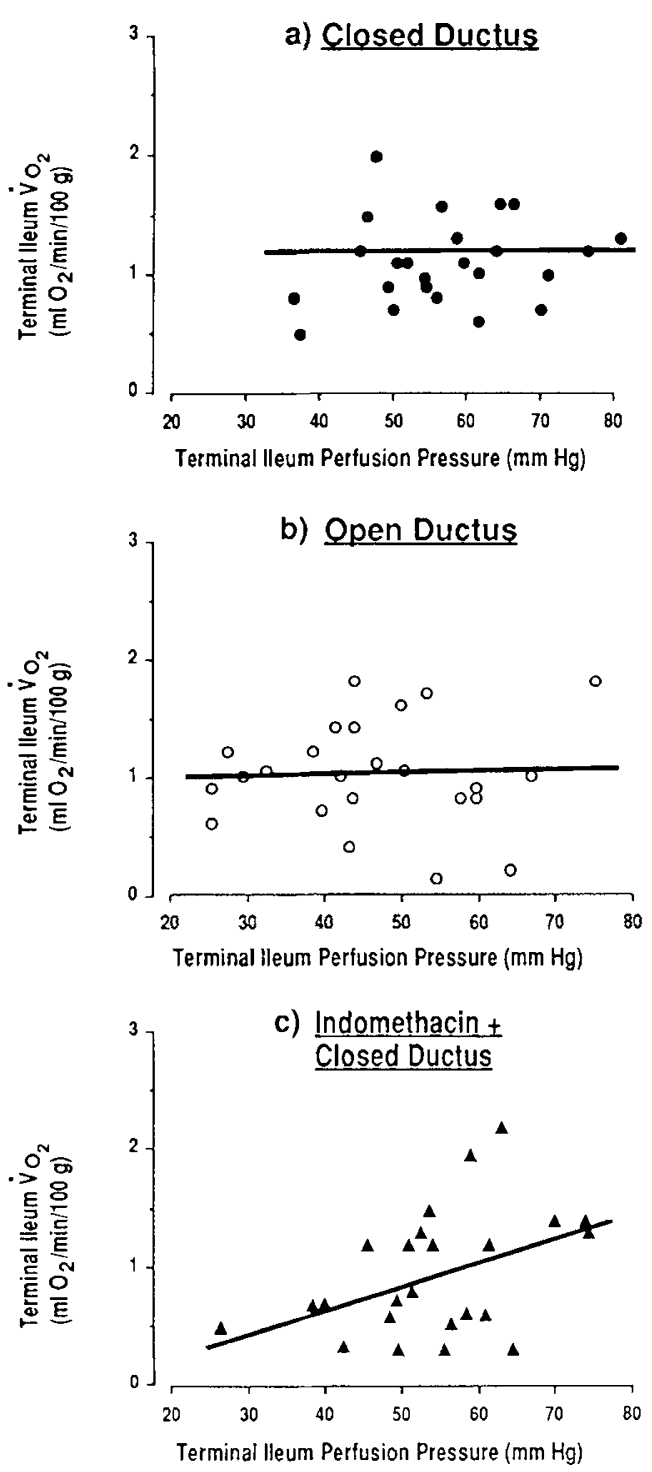

Fig. 2. Autoregulation of terminal ileum oxygen consumption in eight newborn lambs. Terminal ileum perfusion pressure decreased as luminal pressure was increased from $1-2 \mathrm{~mm} \mathrm{Hg}(0.13-0.26 \mathrm{kPa})$ to 18 $\mathrm{mm} \mathrm{Hg}(2.4 \mathrm{kPa})$. The horizontal slope of the regression line in $a$, closed ductus $\left(y=0.003 x+0.928, r^{2}=0.006\right)$ and $b$, open ductus $(y=0.002 x$ $\left.+0.933, r^{2}=0.004\right)$ indicates maintenance, or autoregulation, of terminal ileum oxygen consumption. In $c$, indomethacin + closed ductus, the positive slope of the regression line $\left(\mathrm{y}=0.02 \mathrm{x}-0.1, r^{2}=0.2\right)$ indicates that autoregulation has been compromised $(p<0.05)$.

interesting to note that this compensatory increase in aortic pressure did not occur when the ductus arteriosus was open.

As we increased luminal pressure further to $18 \mathrm{~mm} \mathrm{Hg}(2.38$ $\mathrm{kPa}$ ), the compensatory increase in arterial pressure plateaued, perfusion pressure was decreased, and terminal ileum blood flow fell. The proportionate decrease in blood flow was similar whether the ductus was open or closed, or whether or not the lamb had received indomethacin. It is important to note that the effect of a PDA or indomethacin and superimposed intestinal distension were additive, so that terminal ileum blood flow fell much more when the two factors were combined.

Autoregulation of blood flow is the intrinsic ability of an organ to maintain a relatively constant blood flow despite imposed changes in perfusion pressure (33). In all three conditions in this study, closed ductus, open ductus, and indomethacin + closed ductus, terminal ileum blood flow fell commensurate with the fall in perfusion pressure. Previous studies have shown that some pressure-flow autoregulation exists in the intestine in response to high concentrations of intraluminal solute $(8,34)$. However, in the nonabsorptive state, the quality of intestinal blood flow autoregulation is felt to be marginal $(34,35)$. In our study, the lambs had never been fed, and there was no evidence of terminal ileum blood flow autoregulation.

In adult animals, the intestine appears to autoregulate oxygen uptake and metabolism better than blood flow $(34,35)$. Our study in newborn lambs supports this notion regardless of ductus patency. Whether the ductus was open or closed, a fall in perfusion pressure decreased blood flow, whereas oxygen consumption was relatively maintained (Fig. $2 a$ and $b$ ). This ability to autoregulate intestinal oxygen consumption is thought to occur through an increased efficiency of oxygen extraction by two potential mechanisms $(34,35)$. First, a decrease in intestinal perfusion causes capillary recruitment, which increases the number of actively perfused capillaries (8). In addition, as more capillaries are perfused, the velocity of capillary blood flow decreases, thereby increasing the time available for oxygen exchange (35). Our findings differ from those of Nowicki and Miller (36), who found that oxygen uptake was dependent on arterial pressure in newborn swine. Their studies, however, were performed on isolated and denervated loops of intestine, which might account for the difference in results (36).

We were surprised to discover that pretreatment with indomethacin blocked, or at least severely blunted, autoregulation of terminal ileum oxygen consumption. As shown in Figure $2 c$, as terminal ileum perfusion pressure decreased, so did oxygen consumption. Presumably, indomethacin blocks the compensatory mechanism responsible for capillary recruitment in the intestine. This could be due to either a direct effect of indomethacin or blockade of local prostaglandin synthesis.

In our current study, we focused on PDA and indomethacin because they have both been implicated as significant risk factors in the development of intestinal ischemia and NEC (1-6). Although it is likely that a PDA or indomethacin alone may not be sufficient to produce ischemic injury, they might render the intestine more vulnerable to other ischemic insults. For example, small increases in abdominal pressure (produced by increased diaphragmatic breathing) can decrease intestinal blood flow in lambs with a PDA, but not in lambs whose ductus is closed (13). This hypothesis is consistent with the recent study by Palder $e t$ al. (37), which showed that the severity of NEC is increased in the presence of a PDA.

Whether a direct causal relationship exists between a PDA and NEC remains a matter of debate. In a randomized, controlled trial of prophylactic closure of the ductus arteriosus by surgical ligation, the incidence of NEC was significantly reduced from 30 to $8 \%$ in the early-closure group (2). None of the infants in this study received indomethacin. On the other hand, clinical trials that have used indomethacin to prophylactically close the ductus arteriosus have failed to show any significant effect of early therapy on the incidence of NEC (reviewed in reference 14). Our study suggests that both a PDA and indomethacin present an increased risk of intestinal ischemia. Perhaps indomethacin's beneficial effect on ductus closure is counterbalanced by its negative effect on intestinal perfusion and metabolism. This might account for the failure to see any change in the incidence of NEC after indomethacin-induced ductus closure. In conclusion, our observations help to clarify the relative roles of patent ductus arteriosus, indomethacin, and intestinal distension as factors that increase the risk of intestinal ischemic injury.

Acknowledgments. The authors gratefully acknowledge the technical assistance of Francoise Mauray, Christine Roman, Roger Chang, Carl McWatters, and Bruce Payne, which made completion of this project possible. We also thank Paul Sagan for his skillful editorial assistance. 


\section{REFERENCES}

1. Alpan GM, Eyal F, Vinograd I, Udassin R, Amir GM, Mogle P, Glick B 1985 Localized intestinal perforations after enteral administration of indomethacin in premature infants. J Pediatr 106:277-281

2. Cassady G, Crouse DT, Kirklin JW, Strange MJ, Janier CH, Godoy G, Odrezin GT, Cutter GR, Kirklin JK, Pacifico AD, Collins MV, Lell WA, Satterwhite C, Philips JB 1989 A randomized, controlled trial of very early prophylactic ligation of the ductus arteriosus in babies who weighed $1000 \mathrm{~g}$ or less at birth. N Engl I Med 320:1511-1516

3. Kitterman JA 1975 Effects of intestinal ischemia in necrotizing enterocolitis in the newborn infant. In: 68th Ross Conference on Pediatric Research. Ross Laboratories, Columbus, Ohio, pp 38-41

4. Hervas JA, Masip MC, Alomar A, Bregante JI 1986 Localized intestinal perforation after intravenous indomethacin treatment in a premature infant. Helv Paediatr Acta 41:437-440

5. Vanhaesebrouck P, Thiery M, Leroy JG, Gouaert P, De Praeter C, Coppens M, Cuvelier C, Dhont M 1988 Oligohydramnios, renal insufficiency, and ileal perforation in preterm infants after intrauterine exposure to indomethacin. J Pediatr 1 13:738-743

6. Topalian SL, Ziegler MM 1984 Necrotizing enterocolitis: a review of animal models. J Surg Res 37:320-336

7. Nowicki P 1990 Intestinal ischemia and necrotizing enterocolitis. J Pediatr 117:S14-S19

8. Shepherd AP, Granger DN 1984 Metabolic regulation of the intestinal circulation. In: Shepherd AP, Granger DN (eds) Physiology of the Intestinal Circulation. Raven Press, New York, pp 33-47

9. Bisset WM 1988 Intestinal motor activity in the preterm infant. In: Milla PJ (ed) Disorder of Gastrointestinal Motility in Childhood. John Wiley \& Sons Ltd, New York, pp 29-37

10. Crissinger KD, Granger DN 1988 Characterization of intestinal collateral blood flow in the developing piglet. Pediatr Res 24:473-476

11. Kliegman RM, Fanaroff AA 1984 Necrotizing enterocolitis. N Engl J Med 310:1093-1103

12. Clyman RI, Mauray R, Heymann MA, Roman C 1987 Cardiovascular effects of a patent ductus arteriosus in preterm lambs with respiratory distress. Pediatr 111:579-587

13. Alpan G, Mauray F, Clyman RI 1990 The effects of the patent ductus arteriosus on diaphragmatic blood flow and function. Pediatr Res 10:402-409

14. Clyman RI, Campbell D 1987 Indomethacin therapy for patent ductus arteriosus: when is prophylaxis not prophylactic? J Pediatr 111:718-722

15. Bond JH, Prentiss RA, Levitt MD, Schoenborn K 1980 The effect of anesthesia and laparotomy on blood flow to the stomach, small bowel, and colon of the dog. Surgery 87:313-318

16. Ohman U 1984 The effects of luminal distension and obstruction on the intestinal circulation. In: Shepard AP, Granger DN (eds) Physiology of the Intestinal Circulation. Raven Press, New York, pp 321-334

17. Abe H, Appert HE, Howard JM 1974 Hemodynamic observations of adynamic ileus in the conscious dog. Ann Surg 179:332-338

18. Shikata J, Shida T, Amino K, Ishioka K 1983 Experimental studies on the hemodynamics of the small intestine following increased intraluminal pressure. Surg Gynecol Obstet 156:155-160

19. Ohman U 1976 Blood flow and oxygen consumption in the feline small intestine; responses to artificial distension and intestinal obstruction. Acta Chir Scand 142:329-333

20. Hanson KM 1973 Hemodynamic effects of distension of the dog small intestine. Am J Physiol 225:456-460

21. Ruf W, Suehiro GT, Suehiro A, Pressler V, McNamara JJ 1980 Intestinal blood flow at various intraluminal pressures in the piglet with closed abdomen. Ann Surg 191:157-163

22. Hurley DP, Kremser PC, Gewertz BL 1985 Regulation of intestinal blood flow with increased intraluminal pressure. J Surg Res 39:510-516

23. Bustamonte SA, Srkalovic G, Lundgren O 1989 Hemodynamics during increased intraluminal pressure in the ileum of sucking swine. J Pediatr Gastroenterol Nutr 9:94-97

24. Cronen PW, Nagaraj HS, Janik JS, Groff DB, Passmore JC, Hock CE 1982 Effect of indomethacin on mesenteric circulation in mongrel dogs. J Pediatr Surg 17:474-478

25. Eldridge MW, Kimura RE, Dolcourt JL 1990 Effect of patent ductus arteriosis on superior mesenteric artery blood flow patterns in premature infants. Pediatr Res 27:204A(abstr)

26. Van Bel F, Van Zwieten PHT, Guit GL, Schipper J 1990 Superior mesenteric artery blood flow velocity and estimated volume flow. Radiology 174:165169

27. Chemtob S, Beharry K, Barna T, Aranda JV 1990 Ibuprofen does not compromise ileal and renal hemodynamics in the newborn piglet. Pediatr Res 27:57 A(abstr)

28. Feigen LP, King LW, Ray J, Beckett W, Kadowitz PJ 1981 Differential effects of ibuprofen and indomethacin in the regional circulation of the dog. $J$ Pharmacol Exp Ther 219:679-684

29. Sakanaski M, Aiaki H, Yonemeua K 1980 Indomethacin induced contractions of dog coronary arteries. J Cardiovasc Pharmacol 2:657-665

30. Lippton HL, Armstead WM, Hyman AL, Kadowitz PJ 1987 Characterization of the vasoconstrictor activity of indomethacin in the mesenteric vascular bed of the cat. Prostaglandins Leukotrienes Med 27:81-91

31. Gaffney GR, Williamson HE 1979 Effect of indomethacin and meclofenamate on canine mesenteric and celiac blood flow. Res Commun Chem Pathol Pharmacol 25:165-168

32. Schwartz SI 1989 Manifestations of gastrointestinal disease. In: Schwartz SI, Shires GT, Spencer FC (eds) Principles of Surgery. McGraw-Hill, New York, pp 106I-1102

33. Johnson PC 1964 Review of previous studies and current theories of autoregulation. Circ Res 15:2-9

34. Granger HJ, Norris CP 1980 Intrinsic regulation of intestinal oxygenation in the anaesthetized dog. Am J Physiol 239:H156-H162

35. Bohlen HG 1984 Tissue oxygenation and splanchnic blood flow. In: Shephard AN, Granger DN (eds) Physiology of the Intestinal Circulation. Raven Press, New York, pp 143-151

36. Nowicki PT, Miller CE 1988 Autoregulation in the developing postnatal intestinal circulation. Am J Physiol 254:G189-G193

37. Palder SB, Schwartz MZ. Tyson KRT, Marr C 1988 Association of closure of patent ductus arteriosus and development of necrotizing enterocolitis. $J$ Pediatr Surg 23:422-423 